\title{
Built environments influence carpenter bee sociality and vice versa
}

\author{
M. H. Richards ${ }^{1}$
}

Published online: 25 May 2020

(c) International Union for the Study of Social Insects (IUSSI) 2020

The name Xylocopa literally means "wood-cutter", an apt name for the large, furry carpenter bees that bore tunnels in wood (it is also a more interesting common name than "large carpenter bee"). Most bees nest in relatively soft substrates such as soil or plant stems, which deteriorate without constant maintenance. In contrast, the sturdy nesting substrate used by many carpenter bees, especially those that nest in logs or lumber, deteriorates quite slowly, lasting for years or even decades. This means that nests may be used and re-used for generations. If a female can acquire a nest by inheritance or by quickly usurping a rival, she can avoid days of nest construction. It can take a female carpenter bee the better part of a week or more to excavate a burrow that is just big enough to produce perhaps four or five offspring (Richards and Course 2015). Acquiring access to a pre-existing nest through inheritance, usurpation, or sharing is easier, or at least less time-consuming than excavating a nest from scratch. Across the genus Xylocopa, competition for nests is a fundamental driver of social interactions among females, influencing whether they nest alone or in groups.

Depending on the species, carpenter bee nests may start out as linear structures, with one or two tunnels branching off the nest entrance. Subsequent generations of females may lengthen or add tunnels. Although small nests have less space for brood cells, it is probably easier for occupants to defend the tunnels or entrance and to prevent other females from moving in. Large nests have more space for brood cells but are harder for a single female to monopolize. So, nest structure certainly influence whether carpenter bee females nest solitarily or in groups. It also influences other kinds of social interactions among females: competition for nest ownership or access can be severe, with females engaging in highly aggressive encounters to usurp or defend nest ownership or to establish social hierarchies when two or more

M. H. Richards

mrichards@brocku.ca

1 Brock University, St. Catharines, Canada females occupy the same nest (Gerling and Hermann 1978; Hogendoorn and Leys 1993).

In this issue, Madeleine Ostwald and colleagues investigate the "built environments" of so-called "teddy bear" carpenter bees, Xylocopa varipuncta ${ }^{1}$ (Ostwald et al. 2020). Investigating the built environments of carpenter bees is quite challenging because nests are located inside opaque substrates. While nests can be opened to see what is inside, destructive sampling limits how well we can assess changes in bee colonies or their nests over time. The solution is imaging techniques that allow us to look inside the nests without damaging them. Pioneering studies of carpenter bee behaviour relied on X-rays. Ostwald et al. update this approach using computerized tomography (CT) to scan two logs containing nests of teddy bear bees. Being able to look inside nests revealed changes in bee group size over time. Early in the breeding season (March in Arizona, USA) when females provision brood, most nests contained a single adult, presumably a female (CT scans do not allow females and males to be distinguished) nesting alone, but there was also evidence that some nests contained multiple females. For the rest of the year, nests were mostly occupied by multiple adults, as brood reached adulthood and remained in their natal nests. The number of nests occupied rose and fell throughout the year as some bees moved to new burrows.

A novel angle of this research is demonstrating how nests change size and shape over the course of a breeding season and how this correlates with demographic changes. By imaging the same tunnels repeatedly, Ostwald et al. show that each year, tunnels get a little bit wider. This is because females scrape bits of wood off the sides of tunnels for fashioning into the sawdust partitions that separate brood cells. When the tunnels get wider, this influences how adult bees interact. Carpenter bees defend nest entrances and tunnels mainly by blocking them-friends may pass each other in tunnels, but foes may not. Once tunnels get too wide, females cannot prevent each other from passing through. When females cannot exclude each

\footnotetext{
${ }^{1}$ Xylocopa varipuncta recently was synonymized with Xylocopa
} sonorina (Sheffield et al. 2020). 
other, then they either have to nest together or have to leave to nest elsewhere. Indeed, abandoned tunnels tend to be wider than those in active use. Another way that females modify nests is by adding and lengthening brood tunnels so they can fit in more brood cells. When nests get big enough, their tunnels inevitably converge, and Ostwald et al. found that in one log, many nests had converged into a huge set of continuous tunnels with multiple entrances. A nest of such size and shape would make it almost impossible for females to nest alone.

"Built environment" is a term used more by urban geographers than by social insect biologists. Using this term, Ostwald and colleagues remind us to widen our perspective and place social insects in a wider context. Both humans and social insects frequently build structures that last longer than their occupants, and this influences not only their own behaviour and fitness but that of their offspring too. Building long-lasting structures sets up opportunities for both kin cooperation and kin competition. In carpenter bees, this has led to the evolution of reproductive strategies such as nest sharing, an important first step on the way to bee-ing social.

\section{References}

Gerling D, Hermann HR (1978) Biology and mating behavior of Xylocopa virginica L. (Hymenoptera, Anthophoridae). Behav Ecol Sociobiol 3:99-111

Hogendoorn K, Leys R (1993) The superseded female's dilemma: ultimate and proximate factors that influence guarding behaviour of the carpenter bee Xylocopa pubescens. Behav Ecol Sociobiol 33:371-381

Ostwald MM, Lyman BR, Shaffer Z, Fewell JH (2020) Temporal and spatial dynamics of carpenter bee sociality revealed by CT imaging. Insect Soc. https://doi.org/10.1007/s00040-020-00761-w

Richards MH, Course C (2015) Ergonomic skew and reproductive queuing based on social and seasonal variation in foraging activity of eastern carpenter bees (Xylocopa virginica). Can J Zool 93:615-625

Sheffield C, Heron J, Musetti L (2020) Xylocopa sonorina Smith, 1874 from Vancouver, British Columbia, Canada (Hymenoptera: Apidae, Xylocopinae) with comments on its taxonomy. Biodivers Data J 8:e49918 